\title{
Low-carbon Economy Development Level Evaluation in Beijing Based on Analytic Hierarchy Process (AHP)
}

\author{
Liefu Zhu, Shuifa Ke \\ School of Agricultural Economics and Rural Development, Renmin University of China, Beijing,100872, \\ China
}

Keywords: Low-carbon economy, Development level evaluation, Beijing, AHP

\begin{abstract}
This paper builds the evaluation index system of the level of low-carbon economy development in Beijing. Using the AHP methods to establish the weight. With these methods to analyze 2004-2014, Beijing's low carbon development and compounding the synthetic index. At last evaluating the results of analysis. Conclusion is that the low-carbon development level from 2004 to 2015, 12 years presented a gradual upward trend. Economy index promotes the low-carbon development, society and the consumption problems is the challenges. Beijing's energy structure adjustment is reasonable, science and technology provides a good support. Traffic and environmental needs improving.
\end{abstract}

\section{Introduction}

In recent years, the sustained growth of economic size and population of the world, it is accompanied by greenhouse gases such as carbon dioxide concentration in the atmosphere increased, the greenhouse effect caused by climate change and related issues have become increasingly prominent. Therefore, countries have taken measures to control greenhouse gas emissions, and actively respond to climate change. The concept of "low carbon economic development" has become an inevitable means and path for all countries in the world to achieve sustainable development. This paper sets up a low carbon comprehensive development evaluation index system covering 7 levels of economy, consumption, society and so on, to study the trend and level of low-carbon development in Beijing during the past 2004-2015 years, and make a longitudinal comparison.

Based on the literature research, made a lot of achievements and great progress of domestic scholars on the level of low carbon development evaluation of Beijing City, but the study also has some limitations, such as setting up index system is not perfect, the lack of systematic analysis, the correlation between the indexes is not considered. In the use of methods, qualitative methods are more, quantitative research is less, quantitative methods mainly use AHP and principal component analysis, subjective factors cannot be better overcome.

\section{Construction of Index System}

For the construction of the evaluation index of the low carbon development level of Beijing, this paper puts forward the goal of "humanities, Beijing, science and technology, Beijing and green Beijing" according to the municipal government, and a series of requirements of economic and social development. Comprehensive literature method, expert scoring results to design a set of evaluation index system, the target layer is the level of low carbon development in Beijing City, the criterion layer with the spirit of science, comprehensive, representative and systematic design for economic, energy, environment, society, transportation, life, science and technology and other 7 subsystems. The specific index layer is designed to be 29 indicators of the above 7 systems, such as per capita area GDP, unit GDP energy consumption, CPI and respirable particulate matter. 
Then, to determine the weight of the index, this paper uses the analytic hierarchy process (AHP). Specific methods are divided into the following steps:

Some experts on the ecological environment and low carbon research areas and green economic evaluation and prediction have been investigated and scored by experts. The experts are mainly from universities, forestry and environment, science and technology departments. The purpose of the survey is to apply the collective wisdom of experts to assess the relative importance of various factors at all levels of low carbon development. At present, nearly 20 experts from China sent out expert scoring tables and recovered 11 copies. According to the scoring table and the importance of the expert, the judgment matrix is constructed synthetically. Through calculating weights, standardized processing of indexes and comprehensive evaluation of indexes, the index weight distribution is obtained.

\section{Evaluation Results and Discussion}

Beijing City, according to each index data of 2004-2015 (data from Chinese statistical yearbook, China City Yearbook, Beijing Statistical Yearbook), standardized data processing advanced, then using the above formula, was synthesized by seven subsystems of index 12 years in Beijing city and the comprehensive development level index, further processing to get the score.

Table 1. Measure results of Beijing's development index

\begin{tabular}{ccccccccc}
\hline Year & $\begin{array}{c}\text { Economi } \\
\text { c index }\end{array}$ & $\begin{array}{c}\text { Consum Technol } \\
\text { index }\end{array}$ & $\begin{array}{c}\text { ogy } \\
\text { index }\end{array}$ & $\begin{array}{c}\text { Social } \\
\text { index }\end{array}$ & $\begin{array}{c}\text { Traffic } \\
\text { index }\end{array}$ & $\begin{array}{c}\text { Energy } \\
\text { index }\end{array}$ & $\begin{array}{c}\text { Environ } \\
\text { mental } \\
\text { index, }\end{array}$ & $\begin{array}{c}\text { Composi } \\
\text { te index }\end{array}$ \\
\hline $\mathbf{2 0 0 4}$ & 26 & 74 & 11 & 91 & 87 & 13 & 13 & 30 \\
\hline $\mathbf{2 0 0 5}$ & 26 & 69 & 17 & 67 & 43 & 11 & 26 & 28 \\
\hline $\mathbf{2 0 0 6}$ & 38 & 73 & 41 & 64 & 66 & 14 & 23 & 35 \\
\hline $\mathbf{2 0 0 7}$ & 51 & 68 & 30 & 50 & 31 & 38 & 35 & 42 \\
\hline $\mathbf{2 0 0 8}$ & 40 & 49 & 32 & 48 & 62 & 38 & 57 & 46 \\
\hline $\mathbf{2 0 0 9}$ & 47 & 96 & 40 & 44 & 45 & 41 & 65 & 53 \\
\hline $\mathbf{2 0 1 0}$ & 53 & 77 & 57 & 34 & 19 & 39 & 66 & 51 \\
\hline $\mathbf{2 0 1 1}$ & 52 & 55 & 46 & 25 & 24 & 75 & 77 & 59 \\
\hline $\mathbf{2 0 1 2}$ & 56 & 70 & 56 & 19 & 50 & 59 & 85 & 63 \\
\hline $\mathbf{2 0 1 3}$ & 63 & 72 & 69 & 16 & 81 & 64 & 81 & 69 \\
\hline $\mathbf{2 0 1 4}$ & 67 & 79 & 77 & 12 & 84 & 74 & 82 & 74 \\
\hline $\mathbf{2 0 1 5}$ & 72 & 27 & 88 & 19 & 77 & 77 & 91 & 75 \\
\hline
\end{tabular}

We can get the following results: the progress of Beijing city has made in the development of low carbon 2004-2015 in these 12 years is obvious, the level of low carbon development index rose from 30 in 2004 to 75 in 2015, achieved rapid growth, the development strategy of low carbon city of Beijing played a more visible role has also been strong. The corresponding results. From the data in Table 2, it is found that the social index is declining with the growth of the year, indicating that social and population problems are becoming more and more stressful in low carbon development. In addition to the cost of living index and traffic index fluctuated, the other four indices are showing a steady upward trend, indicating that prices of consumer issues such as we have yet to be resolved, in addition to low carbon transportation development also still faces enormous obstacles, energy saving and emission reduction verification test. The environment index is the direct reflection of low carbon development and results show, but in recent years the development of some slow, haze problems such as the naked eye can see everyone, so we still need to improve environmental governance. 
Social life and consumption, the disposable income of urban residents doubled in 11 years, purchasing power increased significantly, while income increased, prices also rose with the increase of three. CPI now there has been a continuous decline in 49 months, the rapid rise in 2011, now back to 1 era (this year rose $1.6 \%$ ), we can see a series of changes brought about by the development of low carbon economy, has played a certain role.

Energy science and technology, the unit GDP energy consumption, a key data and unit GDP power consumption, shows that we are developing the economy, at the same time, energy consumption is gradually reduced. Horizontal contrast, Beijing has been in the country's leading position in the implementation of energy recycling, energy-saving laws and regulations. Overall, these data reflect the progress of low-carbon development in Beijing.

Traffic and environment, according to data, Beijing in traffic and environment to strengthen the greater strength of development and governance, but the effect is still unsatisfactory from the data point of view. Traffic management measures adopted in recent years, to reduce carbon emissions, alleviate traffic congestion in the city is more and more serious, including a series of comprehensive control measures of staggering work, motor vehicle tail number limit line, opening up the bus lanes, increase the elimination of the old yellow car and efforts to improve the vehicle fuel standards, the implementation of differentiated parking fees. It seems from the data, Beijing city environmental protection pressure is still large, but the solution of the problem is not a single environment from the start can do, cause complex effects caused by a variety of factors, is the most intuitive reflection of the effect of low carbon development. Therefore, all government departments should pay more attention to them and actively coordinate their responses.

To sum up, Beijing is still more obvious low-carbon development effect, the main reason for the author believes that there are several points: first, regional advantages, as the capital of the country, and successfully bid for the Olympic games. The state has also attached great importance to it. Under the stimulation and supervision of policies, regulations and the international environment, the low-carbon development of Beijing has obvious advantages over other regions in china. The two is the industrial advantages, optimize the industrial structure in Beijing city is faster, the proportion of the third industry and practitioners have reached a considerable number, which makes Beijing city still has great potential in the transformation and development of low carbon economy. Three is the scientific and technological advantages, Beijing gathered a considerable part of the national science and technology enterprises, as well as scientific research institutions and institutions of higher learning, both in theory and technology have received very important support. Four is the comprehensive advantage, there is no obvious short board in the low-carbon development of Beijing, complementary resources, and the adjustment of industrial structure is relatively smooth. The government guidance and development mechanism has been gradually established. Energy conservation and emission reduction efforts are also increasing, and ecological environment construction is also beginning to bear fruit.

Of course, in addition to these advantages, Beijing is also facing some development resistance and bottlenecks, first, social problems, population density continues to increase, the natural environment and resources pressure cannot be underestimated. Two is traffic problems, Beijing motor vehicle energy saving emission reduction and congestion problems, although through a variety of measures, including the development of public transport, the elimination of yellow car, limited number of adjustment, the result is still not obvious. The three is environmental problems, Beijing air quality better than two, the number of days accounted for or continued to decline, PM2.5 plagued all citizens. This problem is the most direct reflection of the environmental problems in Beijing, and environmental governance is still a long way to go.

\section{Conclusions and Suggestions}

In this paper, low carbon development level evaluation index of Beijing city conducted a preliminary design of the index system covers more comprehensive development, is also looking for a 
relatively high correlation index and low carbon, processing and the quantitative indicators, the comprehensive evaluation results of Beijing city is relatively long period of low carbon development level. Low carbon development level in Beijing city showed a steady upward trend, the economy is good, natural resources and energy conservation and the development of science and technology to contribute to the development of low carbon city in Beijing; social and living consumption issues constitute the reverse factors of low carbon development, need to be properly resolved; traffic and environmental problems is the most the problems people concern, but the level of development is not obvious, it is also a key problem to be solved urgently. Hope that in 13th Five-Year planned to pay attention and solve the government.

For the current situation of Beijing's low-carbon development strategy, the author has the following four suggestions: first, continue to deepen the industrial structure and energy structure adjustment, and systematically tap the structure to promote potential. Two is the use of scientific and technological innovation and low-carbon service industry to promote low-carbon development, providing technical support, intellectual support and service support for energy conservation and emission reduction. Three is to implement the transportation, environmental protection and other fields key projects, strengthen energy conservation, carbon emission reduction capacity, strengthen management and law enforcement efforts. Four is to guide people to participate in energy-saving emission reduction activities, increase publicity, foster low-carbon culture.

\section{Acknowledgements}

This research is financially supported by Beijing Natural Science Foundation named "Factors of Carbon Emission, Reduction Potential and Low Carbon Development Strategy" (Grant No. 9132012).

\section{References}

[1] Yu Yan, Lu Xinhai. Low Carbon Real Estate Development Problems and Countermeasures of China [J]. Urban Development Studies, 2010, 17(5): 48-51.

[2] Long Weiding, Bai Wei, Liang Hao, Fan Rui, Zhang Gaijing. Urban Form and Energy Vision in Low-carbon Cities [J]. Building Science, 2010, 26(2): 13-18+23.

[3] Chen Yue, Wang Wentao, Fan Ying. A Review of the Research on the Evaluation of Regional Low-carbon Economy Development [J]. China Population, Resources and Environment, 2013, 23(4): 124-130.

[4] Qu Xiaoe, Cao Ke. Development evaluation of low-carbon economy in Shaanxi Province [J]. Journal of Arid Land Resources and Environment, 2013, 27(2): 30-35. 